\title{
Strengthening of steel structures with fatigue cracks using adhesively bonded non-prestressed and prestressed CFRP lamellas
}

\author{
Yvonne Ciupack ${ }^{1}$, Lukas Ledecky², Yann Kasper ${ }^{3}$, Achim Geßler $^{4}$, Matthias Albiez ${ }^{5}$, \\ Hartmut Pasternak ${ }^{6}$, Thomas Ummenhofer ${ }^{7}$, Markus Feldmann ${ }^{8}$ \\ 1, 2, ${ }^{6}$ Chair of Steel and Timber Structures, Brandenburg University of Technology, Cottbus, Germany \\ 3, 5, ${ }^{7}$ Research Center for Steel, Timber and Masonry, Karlsruhe Institute of Technology (KIT), Karlsruhe, Germany \\ ${ }^{4,8}$ Institute of Steel Construction, RWTH Aachen University, Aachen, Germany \\ E-mail: 'yvonne.ciupack@b-tu.de (correspondingauthor)
}

\begin{abstract}
In comparison to classic strengthening methods of fatigue-damaged steel structures, adhesively bonded CFRP lamellas show several advantages. Compared to bolted reinforcement measures and the drilling of the crack tip, crosssectional weakening is avoided. Heat-induced, negatively acting residual stresses and distortions, usually occurring during repair welding, can also be excluded. Therefore, the effectiveness of adhesively bonded CFRP lamellas to enhance the remaining lifetime of fatigue damaged steel structures is examined in a German research project. Selected results are presented in this paper. To characterize the steel, CFRP and adhesive materials, different tests on small scale specimens are carried out. With the help of fatigue tests on CT-samples the remaining fatigue lifetimes of specimens strengthened with adhesively bonded CFRP lamellas is compared to the remaining lifetimes of specimens strengthened by established methods such as drilling the crack tip and repair welding. Based on the evaluation of the crack propagation after the rehabilitation measures, the great potential of adhesively bonded CFRP reinforcements can be deduced. By prestressing the lamellas, the remaining lifetime can generally be increased further. The combination of adhesively bonded CFRP lamellas together with established rehabilitation methods shows a particularly high positive influence on the remaining lifetime of the CT-specimens.
\end{abstract}

Keywords: adhesive, fatigue, CFRP material, crack repair, steel construction.

\section{Introduction}

Adhesive technology has become indispensable in many industrial sectors like the packaging and electrical industry. In the automotive and aerospace industry this joining method has greatly increased in importance in the last decades. However, structural bonding is currently barely present in the construction industry, even though several examples of load-bearing bondlines clearly show the high potential (Hagl, 2002). The rapidly advancing developments in adhesive technology as well as growing demands in steel construction, e.g. for light and filigree structures, lead to an increasing interest in adhesively bonded joints. This is reflected in numerous research efforts, some of which are exemplary presented in the following. In order to avoid stability failure of thin-walled profiles and to increase the load bearing capacity of knee frames with slender webs, adhesively bonded reinforcements provide an innovative solution. This possibility is discussed in (Pasternak \& Meinz, 2006). Feldmann (Feldmann et al., 2006) presents adhesively bonded hollow slab elements as an alternative to conventional, welded orthotropic slabs. An aesthetically pleasing use of structural adhesive bonds was investigated in the European research project INNOGLAST (Feldmann, Abeln, \& Baitinger, 2010). The aim was to validate the load carrying capacity of hybrid steel-glass beams, whereby the flanges were made of steel and the web was made of glass. The compound of the materials was realized using a linear adhesive layer. Bonded façade connections, hollow profile reinforcements and bridge deck constructions were investigated in another research project (Pasternak et al., 2008). Here, a holistic approach was followed with regard to the load carrying capacity, serviceability and reproducibility of the construction. The investigations on adhesively bonded hollow profile reinforcements and trapezoidal profile connections continued in the projects IGF-Project No. 16494 BG (2012) and IGF-Project No. 18161 BG (2017). Here, design concepts were developed and calibrated regarding the recommendations of Eurocode, and initial investigations were made regarding the fatigue resistance of adhesively bonded façade elements. In several research projects, failure criteria for elastic (Bues et al., 2019) and structural adhesives (Albiez,

(C) 2019 Authors. Published by VGTU Press. This is an open-access article distributed under the terms of the Creative Commons Attribution (http://creativecommons.org/licenses/by/4.0/) License, which permits unrestricted use, distribution, and reproduction in any medium, provided the original author and source are credited. 
Vallée, Fricke, \& Ummenhofer, 2019a; Albiez, Vallée, \& Ummenhofer, 2019b) have been developed for the dimensioning of adhesive bond stresses by different interacting stress components. In (Stojkovic \& Pasternak, 2014) a simplified two-parametric model for the estimation of the damage accumulation in an adhesive layer was developed. A possible application of CFRP lamellas to enhance the static load carrying capacity of steel structures was investigated in the project STAKOK (IGF-Project-No. 17700 BG, 2015; Pasternak et al., 2016).

The results of these studies clearly show the significant advantages of adhesive bonding, especially in comparison to the classical joining methods in steel constructions. According to a study by the German Institute for Urban Studies (difu, 2013), Germany's road bridges are in need of renovation and must be replaced or repaired by 2030 in many times. Therefore, investments in the amount of 16 to 17 billion $€$ are necessary. Thus the economic benefits of efficient rehabilitation methods for steel structures are enormous. In a national research project, the effectiveness of currently used crack repair methods and adhesively bonded CFRP lamellas is compared regarding the remaining lifetime of fatigue damaged steel structures. Selected results are presented in this paper.

\section{Crack repair and retrofitting - state of the art}

If fatigue cracks are detected during the inspection of a steel structure, it is desirable to rehabilitate and restore the required load-bearing capacity to prevent structural failure. Currently there are several rehabilitation methods available. In any case, first the crack geometry must be detected, e.g. by non-destructive testing methods like magnetic powder, dye penetration or eddy current method. To remove the sharp notch at the crack tip by an immediate measure, the crack tip can be drilled. However, such boreholes often become origins for new cracks (Sedlacek et al., 2011). Further, repair welding is a widely known technique that can enhance the remaining service life of the fatigue-damaged steel structure. In this case, the crack is completely milled and then welded. In some cases, it may also be necessary to attach local reinforcements through bolted or welded steel components. Depending on the requirements, the different rehabilitation measures can be combined to increase the effectiveness. An essential disadvantage of these described procedures are the notches introduced by the repair itself. During cyclic loading new cracks often originate at places with crosssectional weakening due to drilling of the crack tip or bolting. Because of the high heat input during the welding process, negatively acting residual stresses and microstructural changes promote cracking. By using high frequency hammer peening methods, the negative influences from residual stresses and notch effects can be counteracted (Günther \& Kuhlmann, 2009). Also, welding should be carried out only during periods of reduced traffic (Hanswille \& Piel, 2007), because a relative displacement of the components to be welded can significantly affect the quality of the welds and render the repair obsolete. In addition, repair welding is not possible for some historic steels, such as puddle steel, which was mainly used until 1900, due to the irregularly distributed lamellar slag inclusions (Lüddecke, 2018).

Adhesively bonded CFRP lamellas can offer a solution without the disadvantages described above. Carbon fiber reinforced plastics (CFRP) are characterized by their high tensile strength and modulus of elasticity - similar to steel at a very low dead weight. Furthermore, CFRP materials are highly resistant to corrosion and fatigue (Dehn, 2005). First experiences of this reinforcement method are described in (Hollaway \& Cadei, 2002) and (Shaat, Schnerch, Fam \& Rizkalla, 2004) regarding both static as well as cyclic loading. In (Jiao, Mashiri \& Zhao, 2012), a comparison of different methods for strengthening fatigue-damaged steel components with welded steel sheets and bonded CFRP laminates is given. Recommendations for reinforcing steel constructions with bonded CFRP materials can be found in the "CIRIA Design Guide" (Cadei, Stratfor, Hollaway \& Duckett, 2004). Despite the high potential, steel constructions are still rarely reinforced with CFRP yet. In concrete construction on the other hand, CFRP can be used as bending or transverse force reinforcement, strapping reinforcement of columns as well as for local strengthening measures according to technical approvals. In the case of increased demands on the rehabilitation, the CFRP strips can be prestressed by special devices. Compared with steel structures, however, the concrete surface is the weakest link in the composite cross-section of concrete, CFRP and adhesive layer. Thus, the established adhesive systems of the approved solutions in concrete construction are not transferable to steel construction, as has been showed in a previous project STAKOK (Pasternak et al., 2016).

\section{Crack repair and retrofitting using CFRP}

\section{Characterization of materials}

When designing reinforcement measures with adhesively bonded CFRP laminates, it is necessary to know the material properties. For this purpose, experimental tests on CFRP lamellas and two different epoxy adhesives are carried out. Both adhesives are two-component systems based on epoxy resin. The CFRP lamellas with a thickness of $1.5 \mathrm{~mm}$ and a width of $20 \mathrm{~mm}$ are tested in a tensile test in accordance with DIN EN ISO 527-4 at the BTU Cottbus. The material behavior can be described as quasi-linear with brittle failure. On average, the test specimens have a tensile strength of $3400 \mathrm{MPa}$ and a Young's modulus of $192.000 \mathrm{MPa}$. Adhesive substance samples according to DIN EN ISO 527 are used to characterize the tensile properties of the adhesive bulks. For this purpose, dumbbell specimens (see Figure 1a) are manufactured by injection and subsequently subjected to a tensile test at a strain rate of $1 \% / \mathrm{min}$ at 
RWTH Aachen University. Because adhesively bonded reinforcements are mainly subjected to shear deformations, the shear behavior of the adhesive layer is of particular interest. This is determined by means of lap shear tests in accordance with DIN EN 14869-2 at RWTH, whereby a modification of the test specimens according to (Meschut, Teutenberg \& Wünsche, 2015) is applied in order to take into account the adhesion on the steel and the CFRP surfaces (see Figure 1b). The experiment is carried out displacement-controlled at a speed of $0.9 \mathrm{~mm} / \mathrm{min}$ until the bondline fails. Due to the fact that adhesive layers may react with significant strength losses when subjected to increasing temperature (Ciupack, Pasternak, Mette, Stammen, \& Dilger, 2017), the tests are performed at different temperatures. Exemplary the shear deformation behavior for the adhesives at an ambient temperature of $23{ }^{\circ} \mathrm{C}$ and $80{ }^{\circ} \mathrm{C}$ is shown in Figure 1c. The characteristic decrease of the shear strength and the stiffness with increasing temperature can be seen. The results are summarized in Table 1 for both adhesives Epoxy 1 and Epoxy 2. In all experiments, substrate-near cohesive failure could be detected.
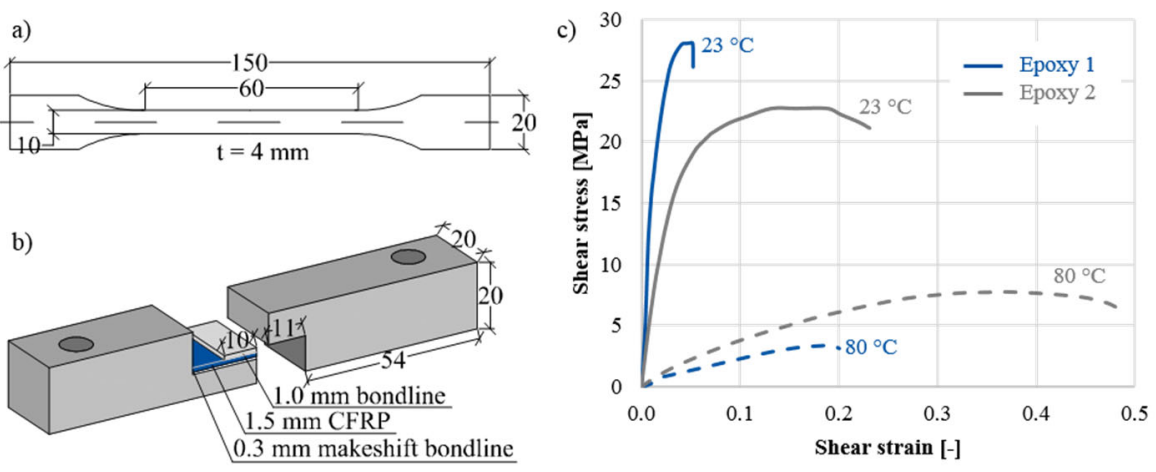

Figure 1. a) Dumbbell specimen; b) Modified lap shear specimen; c) Stress-strain-curves for two adhesives and temperatures

Table 1. Material properties for two selected adhesives

\begin{tabular}{|c|c|c|c|c|c|c|c|c|}
\hline Material properties & \multicolumn{4}{|c|}{ Epoxy 1} & \multicolumn{4}{|c|}{ Epoxy 2} \\
\hline Elastic Modulus [MPa] & \multicolumn{4}{|c|}{8812} & \multicolumn{4}{|c|}{3858} \\
\hline Tensile strength [MPa] & \multicolumn{4}{|c|}{33.5} & \multicolumn{4}{|c|}{23.1} \\
\hline \multirow{2}{*}{ Shear strength at Temperature $[\mathrm{MPa}]$} & $-30^{\circ} \mathrm{C}$ & $23^{\circ} \mathrm{C}$ & $50^{\circ} \mathrm{C}$ & $80^{\circ} \mathrm{C}$ & $-30^{\circ} \mathrm{C}$ & $23^{\circ} \mathrm{C}$ & $50{ }^{\circ} \mathrm{C}$ & $80^{\circ} \mathrm{C}$ \\
\hline & 33.3 & 32.6 & 4.8 & 3.4 & 37.2 & 24.4 & 14.9 & 9.9 \\
\hline
\end{tabular}

As can be seen from the test results in Table 1, the adhesives differ in their mechanical behavior. Epoxy 2 allows for larger deformations (Figure 1), which could be beneficial concerning a possible detachment of the lamella under fatigue loading. On the other hand, Epoxy 1 has a higher tensile strength and higher elastic modulus and reacts more sensitively to the temperature influence. Thus, the shear strength decreases at $80{ }^{\circ} \mathrm{C}$ about $90 \%$ compared to the reference strength at room temperature $\left(23^{\circ} \mathrm{C}\right)$. At $80^{\circ} \mathrm{C}$ Epoxy 2 still has a shear strength of about $40 \%$ of the initial value. For crack repair in steel constructions with adhesively bonded lamellas it may be advantageous to prestress the lamellas. Therefore, an investigation of the creep behavior of the adhesive bond is indispensable. Within the project, modified lap shear samples are stressed for $1000 \mathrm{~h}$ with $40 \%$ of their static shear strength. The mean curves of the deformation-time curves are shown in Figure 2 for a temperature range from $-30{ }^{\circ} \mathrm{C}$ to $50{ }^{\circ} \mathrm{C}$.

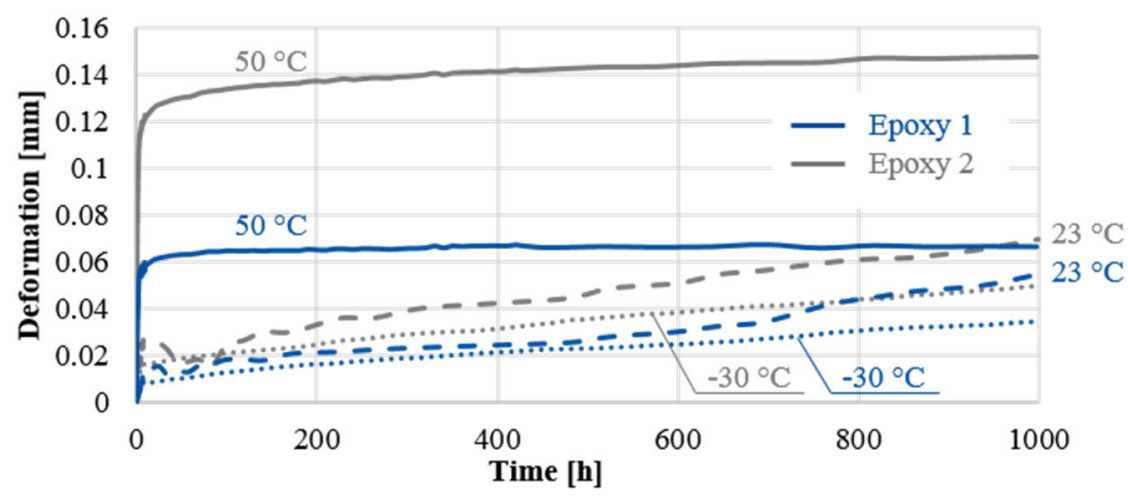

Figure 2. Results of the creep tests 
The determined curves reflect an increase of the creep deformation with higher temperatures. They also confirm that Epoxy 2 has a higher deformation capacity even in the area of secondary creep with constant creeping speed. In this area, weak and strong molecular bonds dissolve, whereby new intermolecular forces can form after a molecular shift (Habenicht, 2009).

All the investigations on the material behavior indicate the need for an exact definition of the application conditions. In order to reinforce steel constructions with adhesively bonded components, it is necessary to consider the external influences on the deformation behavior of the adhesive bonds to select suitable material combinations.

\section{Crack repair and manufacturing of test specimens}

To investigate the influence of adhesively bonded CFRP-reinforcements of fatigue damaged steel structures on the remaining lifetime, experimental investigations are carried out on CT-specimens (compact tension). These specimens are usually used to determine the fracture toughness according to DIN EN ISO 12737. Within the research project, drilling of the crack tip, repair welding and bonding of prestressed and non-prestressed CFRP lamellas as well as combinations of these methods are considered. Figure 3 shows the geometry of the sample and the steps of the established procedures of drilling the crack tip and repair welding.

a)

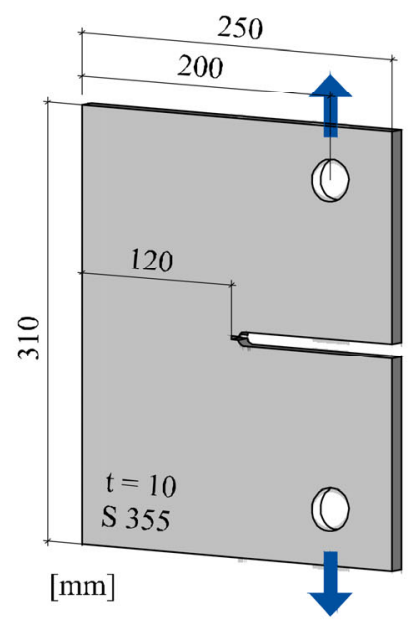

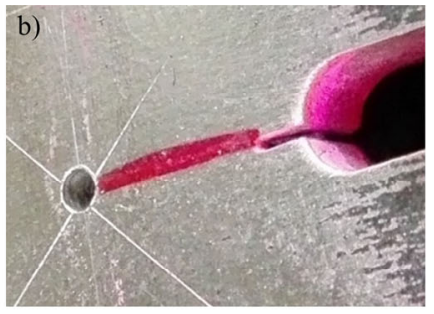

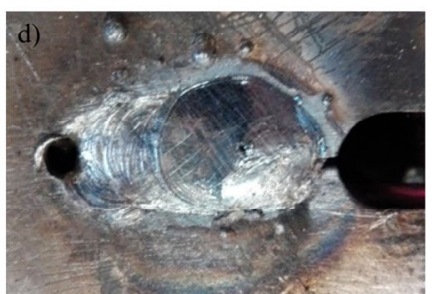

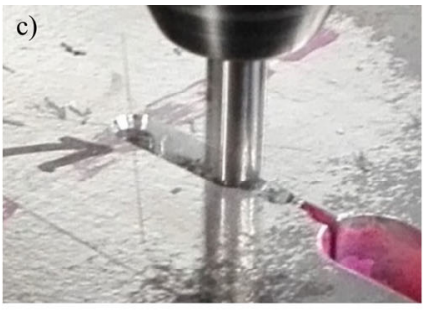

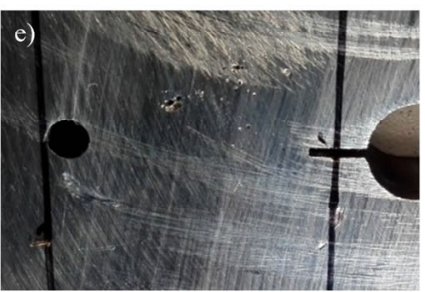

Figure 3. a) CT-specimen; b) Drilling the crack tip (diameter of $4 \mathrm{~mm}$ ); c) Milling of the crack (X-shape); d) Repair welding (arc welding); e) Grinding of the surface

For the specimens reinforced with CFRP lamellas, the steel surface is pretreated by a blasting process. Thus, the adhesion of the adhesive layer on the steel surface can be significantly improved. Before the joining process, the surfaces of the lamella and CT sample are thoroughly cleaned with acetone to remove grease and other contaminants. In order to realize a bondline thickness of $1 \mathrm{~mm}$, glass beads with the appropriate diameter are sprinkled into the applied adhesive bead. Then the prepared lamella is applied and the test specimens cure for at least 7 days at room temperature $\left(23{ }^{\circ} \mathrm{C} \pm 2{ }^{\circ} \mathrm{C}\right.$ and relative humidity $\left.65 \% \pm 4 \%\right)$. In case of applying a prestressed lamella a pretensioning system specially developed for this purpose at the KIT Karlsruhe is used. It consists of a substructure made of a U240 (S355) profile, fixed anchoring points and movable clamping jaws (see Figure 4).
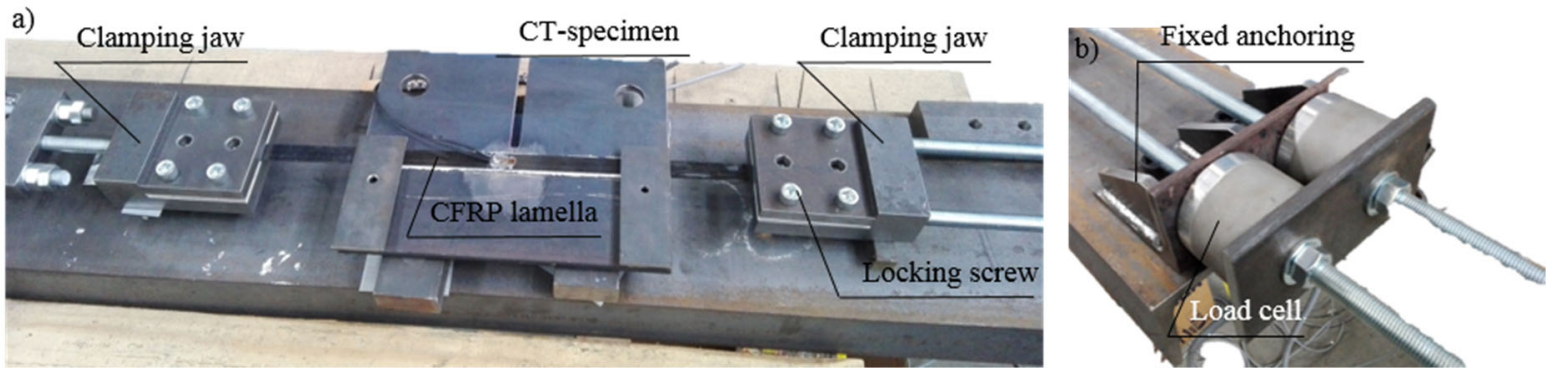

Figure 4. a) Prestressing device with CT-specimen; b) Detail of the anchoring points

In order to prevent slipping of the smooth CFRP surface, blasted aluminum plates are interposed, which provide a higher coefficient of friction and a more uniform distribution of the clamping force. The lamella is fixed by tightening the locking screws at the clamping jaws. A system of threaded rods, nuts and linkages connects the clamping jaws and 
the anchorings. To prestress the lamella the nuts on the fixed anchoring of the pretensioning table are tightened (Figure 4b). For the correct setting of the required preload force, load measurements at one anchorage point and strain measurements on the lamella surface are carried out continuously during the curing time ( 7 days). The specimens with Epoxy 1 are prestressed with $5 \mathrm{kN}$, Epoxy 2 with $3 \mathrm{kN}$ respectively. Before releasing the pretension force and carrying out the fatigue test, final anchoring plates are attached to the lamella ends in order to prevent a premature failure due to high peel stresses.

During the curing process, no preload loss could be registered. It is expected that the pretension force in the lamella declines during the release of the pretension force due to the deformation of the adhesive layer. Therefore, the strains on the lamella surface are measured during the release of the pretension force and a few minutes thereafter. A decrease of the lamella strain can be observed for all test specimens during the release only. Afterwards the pretension force forms a plateau over time. Figure 5a shows the mean time-preload-curves for the adhesives used.
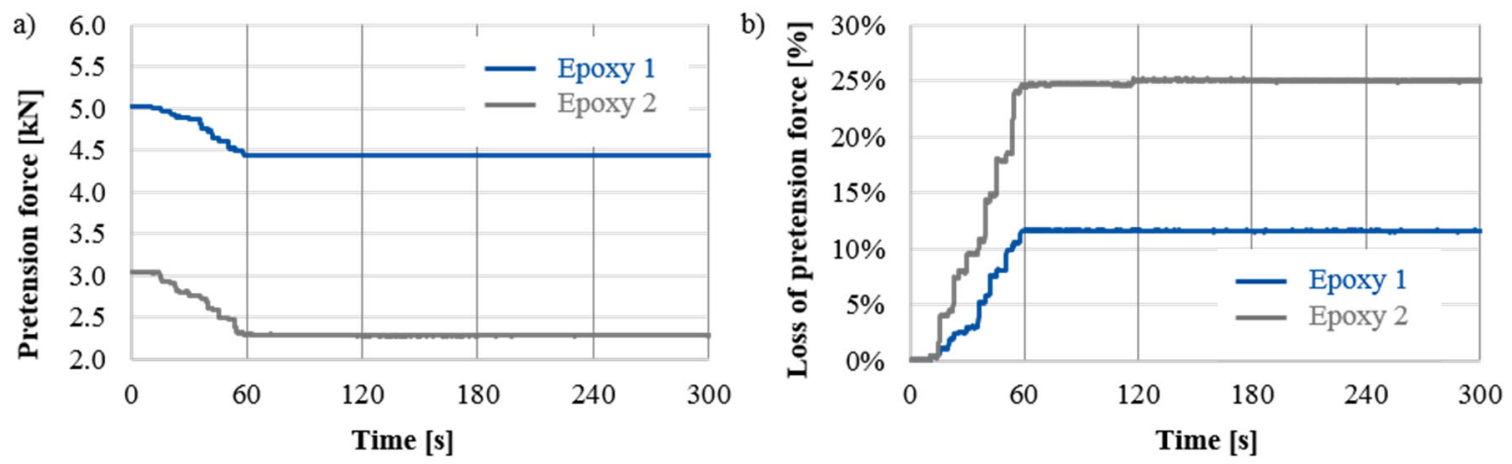

Figure 5. a) Development of the pretension force in the CFRP lamella during relaxation;

b) Pretension load loss during relaxation

For the specimens bonded with Epoxy 2 a higher decrease of the pretension force can be observed (see Figure 5b). This can be explained with the lower stiffness of Epoxy 2, see Table 1. This effect is superimposed by creeping of the adhesive layer. As shown in Figure 2, large creep deformations occur within 7 days (168 hours). Due to the creep behavior, it can be assumed that in a real application the preload force further declines during the service life time compared to the short-term experiments.

\section{Experimental investigations on the crack repair method}

The objective of the experimental investigations on CT-specimens is to compare different rehabilitation methods regarding the remaining lifetime of fatigue damaged steel components. Moreover, the effectiveness of adhesively bonded CFRP lamellas should be analyzed. The tests are performed in three phases: In the first phase, the undamaged specimen is fatigue loaded at a frequency of $14 \mathrm{~Hz}$, a stress ratio of $\mathrm{R}=0.5$ and a force amplitude of $10 \mathrm{kN}$. The test is stopped when a $20 \mathrm{~mm}$ long initial crack is formed. In the second phase the crack repair methods as described above are executed. This is followed by cyclic loading of the rehabilitated specimen, regarding the mentioned test conditions, until the crack has grown to a total length of $40 \mathrm{~mm}$ (third test phase). During the test, machine force and displacement as well as the crack propagation using crack measurement sensors are recorded. For all test specimens, which are strengthened with a bonded CFRP lamella, the strains are measured in the center of the lamella surface. The crack propagation curves are given in Figure $6 \mathrm{a}$ to Figure $6 \mathrm{c}$ for the presented repair methods and combinations of these.

The curves only illustrate test phase 3, therefore the crack propagation between $20 \mathrm{~mm}$ and $40 \mathrm{~mm}$ is shown. Figure 6a shows the results for the tests where no drilling of the crack tip is performed. Compared to the reference experiments, a positive effect regarding the remaining lifetime is shown solely on the basis of the adhesively bonded CFRP lamella. This test series shows that the influence of the selected adhesive appears to be subordinate. The remaining lifetime can be increased by $180 \%$ using non-prestressed CFRP lamellas. Prestressing of the lamellas however leads to a slight decrease in the number of sustainable cycles. This is probably caused by the application of a singlesided reinforcement. Due to prestressing, a tensile force is introduced only on one side of the $10 \mathrm{~mm}$ thick steel plate, which causes a secondary bending moment of the specimen and leads to a higher stress intensity at the crack tip on the non-reinforced side during loading.

For an additionally drilled crack tip the crack propagation curves are shown in Figure $6 \mathrm{~b}$. The initial step between $20 \mathrm{~mm}$ and $22 \mathrm{~mm}$ results from the bore hole with a diameter of $4 \mathrm{~mm}$ (see Figure $7 \mathrm{~b}$ ). Compared to the strengthening with only bonded lamellas, the increase in the remaining lifetime resulting from only drilling the crack tip is less, reaching additional $60 \%$. The application of a prestressed lamella in combination with drilling the crack tip leads to a further increase in the number of bearable cycles by about $300 \%$. In these experiments, no negative influence of the single-sided prestressing can be observed. A possible explanation could be the more homogeneous stress distribution 
at the borehole. To investigate this phenomenon in detail further experiments are needed. In Figure $6 \mathrm{c}$, the crack propagation curves for a rehabilitation combining repair welding, a drilled crack tip and adhesively bonded CFRP lamellas are shown. The results also prove the great potential of the innovative strengthening method. By the application of a non-prestressed lamella an extension of the remaining lifetime of $102 \%$ in average can be achieved. The application of the preload force leads to a 50\% higher remaining lifetime compared with non-prestressed CFRP strips. In combination with repair welding, prestressing is particularly effective. When the crack tip is drilled (without repair welding), prestressing results in an increase of the remaining service life of only $9 \%$ for Epoxy 1 compared to non-prestressed bonded reinforcements, $17 \%$ for Epoxy 2 respectively.

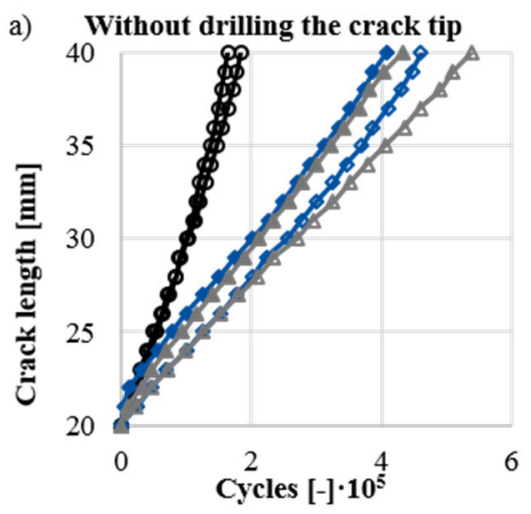

- Without any repair measures

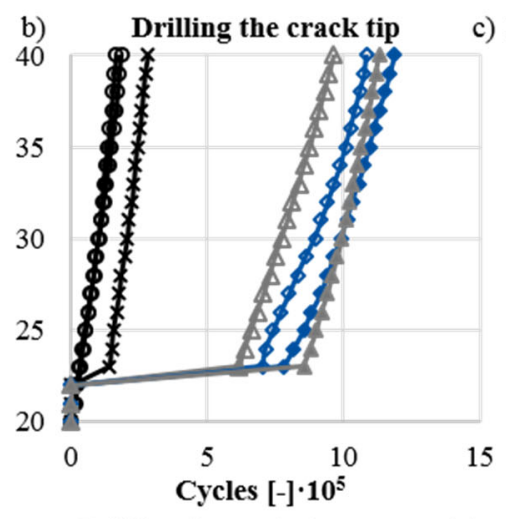

Drilling the crack tip c) Drilling the crack tip and repair welding

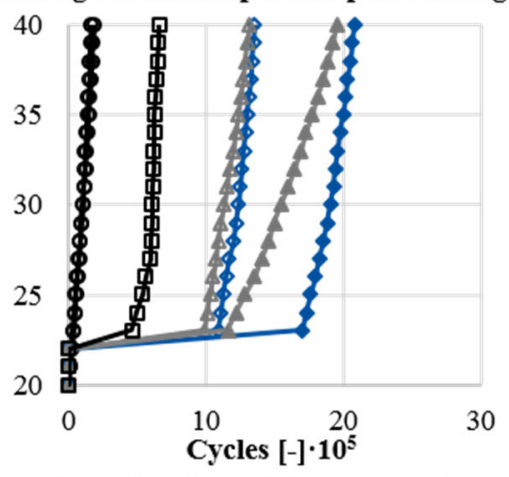

巴 Repair welding (incl. drilling the crack tip)

Epoxy 1 prestressed $\quad-$ Epoxy 2 prestressed

Figure 6. Crack propagation on CT-specimens: a) Without tapping; b) With tapping the crack tip;

c) Repair welding (incl. drilling)

To compare all repair measures and the considered combinations, the experimentally determined number of cycles - up to a total crack length of $40 \mathrm{~mm}$ - are summarized in Figure 7a.

a)

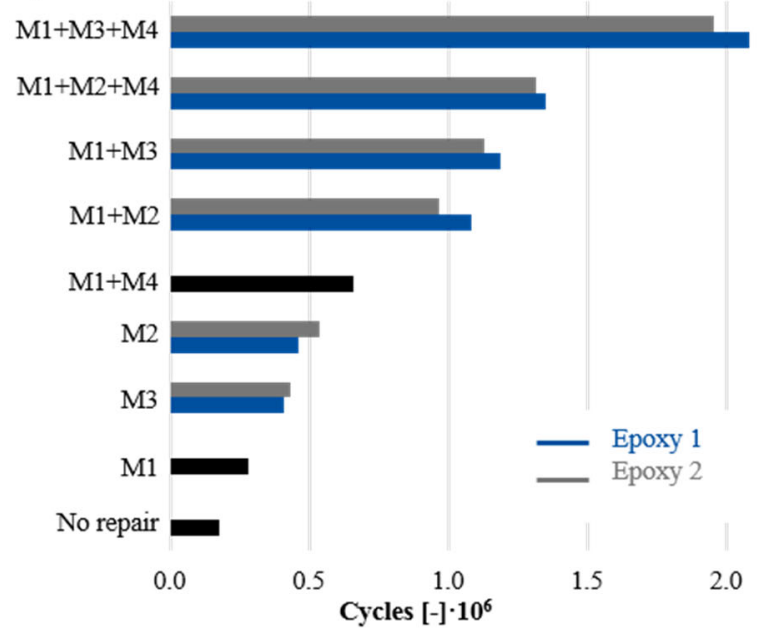

b)

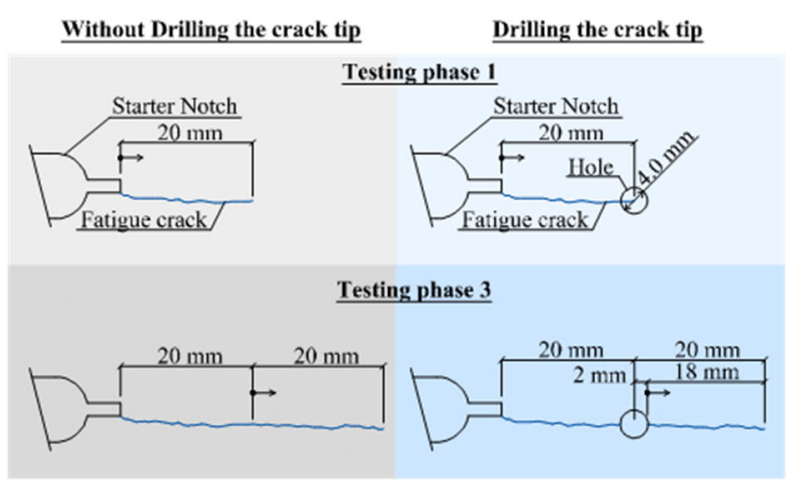

M1 = Drilling of the crack tip; M2 = Non-prestressed CFRP M3 = Prestressed CFRP; M4 = Repair welding

Figure 7. a) Comparison of various crack repairing methods;

b) Schematic crack propagation with and without drilling the crack tip

In all tests, the positive influence of adhesively bonded lamellas on the remaining lifetime of fatigue damaged steel components can be observed. For increased demands on the remaining service life of steel structures, the repair measures can be combined with each other very effectively. 


\section{Numerical simulation}

Selected experiments are also numerically simulated within the project. The extended finite element program XFEM is used within the software package ABAQUS. To avoid the definition of a new mesh after cracking, meshindependent fracture modelling is applied. For the modelling, C3D8 and partly C3D6 elements are used, whereby the element size in the area of the expected crack is selected to be correspondingly small (here: $0.5 \mathrm{~mm}$ ). Figure $8 \mathrm{a}$ shows the numerical model with the mesh for the simulation of the fatigue test on a CT-specimen strengthened with an adhesively bonded CFRP lamella.
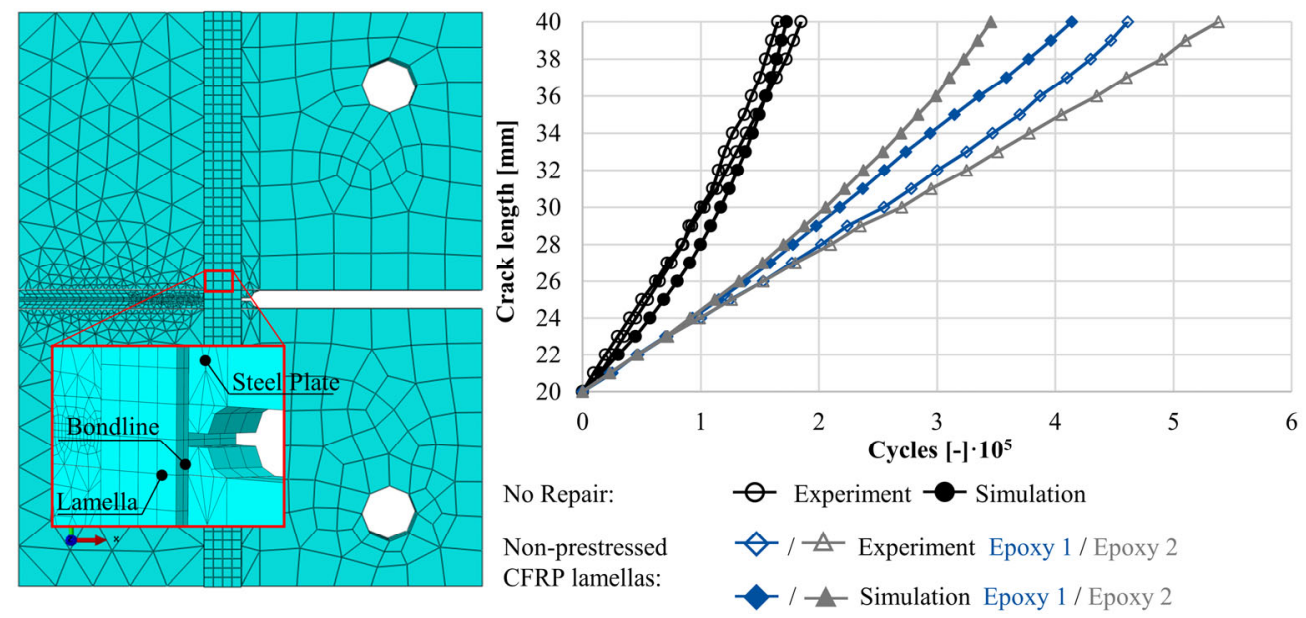

Figure 8. a) FE-Model with detail; b) Crack propagation - comparison of simulation and experiment

The assigned material properties (Young's Modulus and Poisson's ratio) are based on the experimental investigations on CFRP lamellas and the dumbbell specimen of the adhesives previously described. The contact between the individual components is assumed to be quasi-rigid (Tie). Modeling and simulation are performed in three steps: In the first step, the location of the crack initiation is defined manually. This is possible due to the simple geometry. The simulation of the crack growth is carried out in the second step using Paris law to define the relation between crack growth rate and the crack tip intensity. The material constants for crack initiation and crack growth are calibrated on the basis of the reference experiments without repair measures. A very good match between simulation and experiment could be achieved (see Figure 8b). Since the simulation of the individual experimental periods (static, general) would result in very long computation times to simulate the cumulative fatigue, a Fourier series approximation is combined with the temporal integration of the material behavior (direct cyclic). For this, the period duration from the experiments is used and the time increment for the approximation per period is assumed to be $1 / 10$. To speed up the simulation, the forward damage extrapolation is also adopted. Each increment extrapolates the current damaged state in the material over many cycles to a new damaged state after the current load cycle is stabilized.

In Figure 8b, the simulation results for non-prestressed CFRP lamellas (without further repair measures) are compared with the test results (third test phase). As can be seen from the crack propagation curves, the simulation underestimates the remaining service life of the rehabilitated CT-sample. In the case of Epoxy 1 , the difference of $10 \%$ is relatively small, however, for Epoxy 2 the difference is about $35 \%$. These results obtained so far confirm the simulation approach, but further experimental and numerical investigations are required.

\section{Conclusions and outlook}

While reinforcements of concrete constructions using adhesively bonded CFRP materials are state-of-the-art, this method is not yet fully accepted for strengthening steel constructions. In the presented experimental results of tests on CT-samples, the great potential of adhesively bonded non-prestressed and prestressed CFRP lamellas to strengthen fatigue damaged steel components could be demonstrated. By simply adhering a non-prestressed CFRP lamella across a fatigue crack the remaining lifetime can be increased by $180 \%$ compared to an unstrengthened specimen. In combination with established rehabilitation methods, the number of sustainable cycles can be increased by a factor of up to 12. A dependence of the adhesive stiffness on the effectiveness of the strengthening method can be shown partly. In investigations on center-notched steel specimens, this influence could be confirmed (Kasper et al., 2019). Some tests indicate a negative influence of the single-sided application of prestressed CFRP lamellas. Ongoing investigations on center-notched sheets at the KIT Karlsruhe confirm this assumption. At the present time, tests are also being carried out to investigate the influence of creeping of the adhesive at an elevated temperature on the lamella preload force. In 
order to verify the developed strengthening method, an existing bridge structure will be locally strengthened and deformation measurements will be carried out. In addition, the aim is to further improve and validate the presented numerical model.

\section{Acknowledgements}

The IGF research project (IGF-No. 19032 BG/ DVS-no. 09.072) of the "Research Association on Welding and Allied Processes of the DVS, Aachener Straße 172, 40223 Düsseldorf" has been funded by the AiF within the program for sponsorship by Industrial Joint Research (IGF) of the German Federal Ministry of Economic Affairs and Energy, based on an enactment of the German Parliament.

\section{References}

Albiez, M., Vallée, T., Fricke, H., \& Ummenhofer, T. (2019a). Adhesively bonded steel tubes - Part I: Experimental investigations. International Journal of Adhesion and Adhesives, 90(4), 199-210. https://doi.org/10.1016/j.ijadhadh.2018.02.005

Albiez, M., Vallée, T., \& Ummenhofer, T. (2019b). Adhesively bonded steel tubes - Part II: Numerical modelling and strength prediction. International Journal of Adhesion and Adhesives, 90(4), 211-224. https://doi.org/10.1016/j.ijadhadh.2018.02.004

Bues, M., Schuler, C., Albiez, M., Ummenhofer, T., Fricke, H., \& Vallée, T. (2019). Load bearing and failure behaviour of adhesively bonded glass-metal joints in façade structures. The Journal of Adhesion, 95(5-7), 653-674. https://doi.org/10.1080/00218464.2019.1570158

Cadei, J. M. C., Stratford, T. J., Hollaway, L. C., \& Duckett, W. G. (2004). Strengthening metallic structures using externally bonded fibre-reinforced polymers. Design Guide. London: CIRIA. 234 p.

Ciupack, Y., Pasternak, H., Mette, C., Stammen, E., \& Dilger, K. (2017). Adhesive bonding in steel construction - Challenge and innovation. Procedia Engineering, 172, 186-193. https://doi.org/10.1016/j.proeng.2017.02.048

Dehn, F. (2005). Faserverbundwerkstoffe ( $\left.1^{\text {st }} \mathrm{ed}\right)$. Berlin: Bauwerk (Innovationen im Bauwesen - Beiträge aus Praxis und Wissenschaft der Universität Leipzig und der HTWK Leipzig.

difu Deutsches Institut für Urbanistik. (2013). Infrastruktur: Viele kommunale Straßenbrücken müssen bis 2030 neu gebaut werden. Medieninformation vom 30. September 2013. Retrieved from http://www.difu.de/presse/2013-09-30/infrastruktur-viele-kommunale-strassenbruecken-muessen-bis.html

Entwicklung eines Eurocode-basierten Bemessungskonzepts für Klebverbindungen im Stahlbau (in Anlehnung an DIN EN 1990). IGF-Project No. 16494 BG. 05.2010 - 04.2012. (2012). Forschungsvereinigung Stahlanwendung e.V. Report in press.

Feldmann, M., Abeln, B., \& Baitinger, M. (2010, May). Analysis of bonded hybrid steel-glass-beams by small scale tests. In Challenging Glass 2 - Conference on Architectural and Structural Applications of Glass. Delft, Netherlands.

Feldmann, M., Völling, B., Geßler, A., Wellershof, F., Geiß, P. L., \& Wagner, A. (2006). Kleben im Stahlbau. Stahlbau, 75(10), 834-846. https://doi.org/10.1002/stab.200610092

Günther, H.-P., \& Kuhlmann, U. (2009). Nachweiskonzepte zur Bemessung ermüdungsbeanspruchter Bauteile unter Berücksichtigung von Schweißnahtnachbehandlungsverfahren durch höherfrequentes Hämmern. Stahlbau, 78(9), 613-621. https://doi.org/10.1002/stab.200910075

Habenicht, G. (2009). Kleben - Grundlagen, Technologien, Anwendungen ( $6^{\text {th }}$ ed.). Berlin Heidelberg: Springer-Verlag. https://doi.org/10.1007/978-3-540-85266-7

Hagl, A. (2002). Synthese aus Glas und Stahl: Die Herz-Jesu-Kirche München. Stahlbau, 71(7), $498-506$. https://doi.org/10.1002/stab.200201630

Hanswille, G., \& Piel, W. (2007). Gutachterliche Stellungnahme - Sanierung der Schäden an der orthotropen Fahrbahnplatte der Stabbogenbrücke über den Rhein-Herne Kanal im Zuge der A42 - Stellungnahme hinsichtlich zukünftiger Schweißarbeiten unter Verkehr-Bw.-Nr. 4407510A. Landesbetrieb Straßenbau Nordrhein-Westfalen.

Hollaway, L. C., \& Cadei, J. (2002). Progress in the technique of upgrading metallic structures with advanced polymer composites. Progress in Structural Engineering and Materials, 4(2), 131-148. https://doi.org/10.1002/pse.112

Jiao, H., Mashiri, F., \& Zhao, X.-L. (2012). A comparative study on fatigue behaviour of steel beams retrofitted with welding, pultruded CFRP plates and wet layup CFRP sheets. Thin-Walled Structures, 59, 144-152. https://doi.org/10.1016/j.tws.2012.06.002

Kasper, Y., Albiez, M., Ummenhofer, T., Ciupack, Y., Ledecky, L., Pasternak, H., Geßler, A., \& Feldmann, M. (2019). Application of fibre composite materials for the rehabilitation of fatigue damage in steel structures. In The Seventh International Conference on Structural Engineering, Mechanics and Computation. Cape Town, South Africa.

Lüddecke, F. (2018). Ein Beitrag zur Ertüchtigung bestehender Stahltragwerke unter besonderer Berücksichtigung des Fügeverfahrens Schweißen (Dissertation). Technische Universität Dresden.

Meschut, G., Teutenberg, D., \& Wünsche, M. (2015). Prüfkonzept für geklebte Stahl/CFK-Strukturen. adhäsion KLEBEN \& DICHTEN, 59(3), 16-21. https://doi.org/10.1007/s35145-015-0513-6

Pasternak, H., \& Meinz, J. (2006). Versuche zu geklebten Verstärkungen im Stahlhochbau. Bauingenieur, 81 (5), $212-217$.

Pasternak, H., Bartholomé, S., Ummenhofer, T., Götz, F., Feldmann, M., \& Geßler, A. (2016). Verstärkung von Stahlkonstruktionen durch aufgeklebte CFK-Lamellen. In 20. DASt-Forschungskolloquium. Essen, Germany. 
Ciupack, Y.; Ledecky, L.; Kasper, Y.; Geßler, A.; Albiez, M.; Pasternak, H.; Ummenhofer, T.; Feldmann, M. 2019.

Strengthening of steel structures with fatigue cracks using adhesively bonded non-prestressed and prestressed CFRP lamellas

Pasternak, H., Meinz, J., Feldmann, M., Völling, B., Abeln, B., Dilger, K., ..., \& Wagner, A. (2008). Neue Konstruktionen durch Einsatz von Klebverbindungen im Stahlbau. Forschungsbericht für die Praxis P654, (AiF-Projekt No. 169 ZBG)., Forschungsvereinigung Stahlanwendung e. V., Verlags- und Vertriebsgesellschaft, Düsseldorf.

Sedlacek, G., Paschen, M., Feldmann, M., Geßler, A., Möller, S., Steinauer, B., \& Scharnigg, K. (2011). Instandsetzung und Verstärkung von Stahlbrücken unter Berücksichtigung des Belagssystems. Berichte der Bundesanstalt für Straßenwesen Instandsetzung und Verstärkung von Stahlbrücken unter Berücksichtigung des Belagssystems, Brücken- und Ingenieurbau Heft B 76. Bergisch Gladbach: Bundesanstalt für Straßenwesen.

Shaat, A., Schnerch, D., Fam, A., \& Rizkalla, S. (2004). Retrofit of steel structures using Fiber-Reinforced Polymers (FRP): Stateof-the-art. In Transportation Research Board (TRB) Annual Meeting.

Stojkovic, N., \& Pasternak, H. (2014, June). Fatigue of adhesively bonded structural elements - residual strength models. In $14^{\text {th }}$ International Scientific Conference VSU 2014. Sofia, Bulgaria.

Systematische Untersuchungen zur Verstärkung von Stahlkonstruktionen mit kohlefaserverstärkten Kunststoffen (CFK) - STAKOK (IGF-Project-No. 17700 BG. 03.2013 - 09.2015). Forschungsvereinigung Schweißen und verwandte Verfahren e.V. des DVS.

Untersuchungen zum Tragverhalten und der Lebensdauer von Klebverbindungen im Stahlbau unter zyklischer Belastung - LebKleb (IGF-Project No. 18161 BG. 04.2014 - 09.2017). (2017). Forschungsvereinigung Stahlanwendung e.V. Report in press. 